\title{
Growth Differentiation Factor 8 Measurement
}

National Cancer Institute

\section{Source}

National Cancer Institute. Growth Differentiation Factor 8 Measurement. NCI Thesaurus.

Code C135423.

The determination of the amount of growth differentiation factor 8 in a biological sample. 